\title{
Hereditary spastic ataxia with congenital miosis: four cases in one family
}

\author{
DAVID J. DiCK, PETER K. NEWMAN, AND PETER G. CLELAND \\ From the Regional Neurological Centre, Newcastle General Hospital, Newcastle upon Tyne
}

SUMMARY Four cases are described of hereditary spastic ataxia associated with congenital miosis. It is thought that the latter is due to absence of the dilator pupillae muscle. The familial spinocerebellar degenerations are associated with a wide variety of other ocular abnormalities, and these are discussed.

In 1892 Sanger Brown ${ }^{1}$ described a family with hereditary spastic ataxia. Twenty-one patients through 4 generations were described and showed symmetrical ataxia of gait and limb movement, dysarthria, and pyramidal signs in the limbs. Three patients had impaired pupillary reaction to light, and at least one developed a disorder of conjugate eye movement. This is one of the earliest reported ocular associations of the hereditary ataxias, and since then abnormalities have been found in patients with hereditary spastic paraplegia, Friedreich's ataxia, olivo-ponto-cerebellar atrophy, and other less well defined familial ataxias. These range from incidental findings such as coloboma iridis to well known associated abnormalities like optic atrophy, retinal degeneration, and disorders of conjugate gaze.

A family is presented in which the clinical features resemble most closely hereditary spastic ataxia, although, as will be discussed later, there are anomalous features. All 4 patients had a fixed miosis, with an inability to dilate the pupil in response to a reduction in light intensity. Though other pupillary abnormalities have been described, congenital miosis has not to our knowledge been previously reported in association with a familial ataxia.

\section{Case reports}

The family detailed in Fig. 1 was examined and the mother and 3 of her 5 children were found to have abnormal features. The maternal grandmother declined to be examined but to our knowledge was normal. Two of the children were investigated in detail.

Correspondence to Dr D. J. Dick, Regional Neurological Centre, Newcastle General Hospital, Newcastle upon Tyne NE4 6BE.
CASE 1

Mother, aged 44. This patient's history was the least well documented. She had certainly been unsteady since her early teens, but had not deteriorated significantly since then. She had suffered from epilepsy for 20 years, for which she took regular phenobarbitone. General medical examination was normal. Her pupils were $2 \mathrm{~mm}$ in diameter and did not respond to light, dark, or accommodation. Phasic nystagmus was present on up and down gaze but not in the primary position. The optic fundi were normal. Tone and power in the limbs were normal, but there were mild bilateral cerebellar signs in all limbs, and she was unable to do tandem gait. The reflexes were pathologically brisk and the plantar responses flexor. Sensation was normal.

\section{CASE 2}

Eldest son, aged 25 . This patient had been born by spontaneous vertex delivery at term with no postnatal complications. Until the age of 4 he was unable to walk unaided, and his speech was slurred and barely intelligible. He attended a special school where there was little if any progression in his disability, and he currently works as a semiskilled labourer. The abnormal findings were once again confined to the central nervous system. He had normal visual acuity and optic discs. The pupils were small, $2 \mathrm{~mm}$ in diameter, and unreactive to light and accommodation. There was phasic nystagmus in all directions of gaze but not in the primary position. The remainder of the cranial nerves were normal. Examination of the limbs showed a mild generalised increase in tone with normal power. The reflexes were pathologically brisk, but the plantars were flexor. He walked with a spastic ataxic gait, and had moderate upper limb incoordina- 
Fig. 1 Family pedigree. $A+W=$ alive and well.

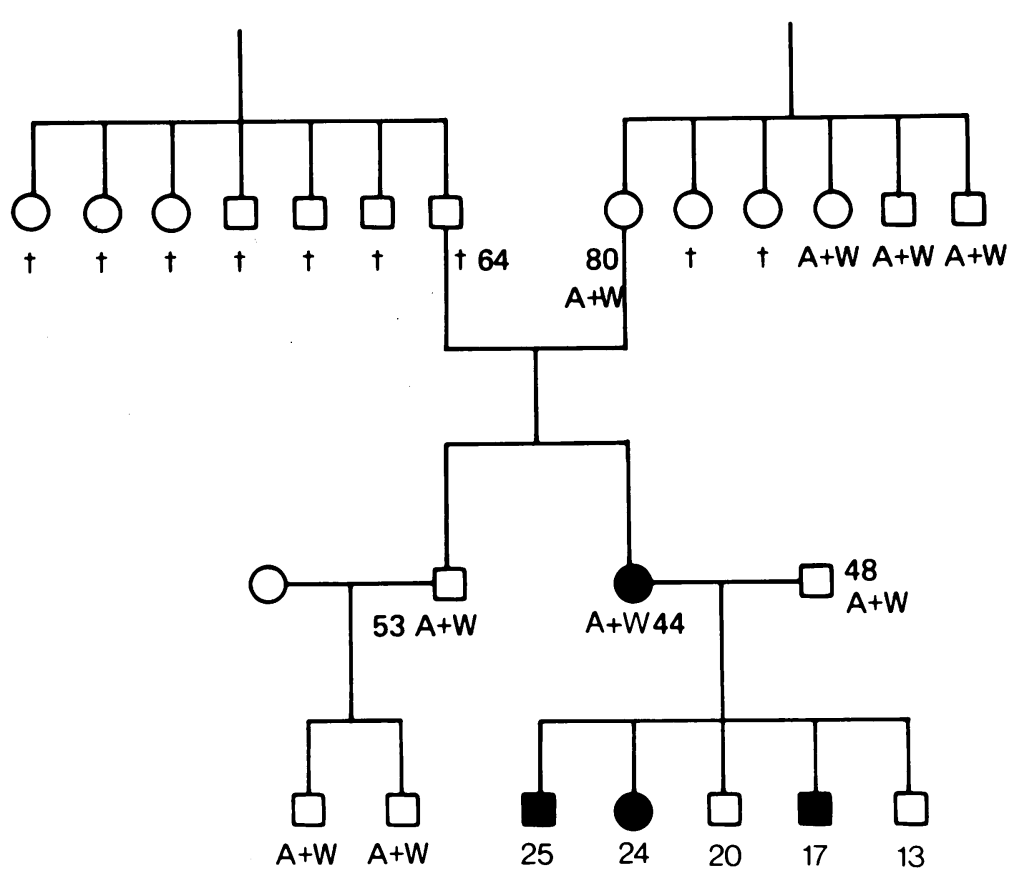

tion and heel-to-shin ataxia. Sensory examination was normal.

\section{CASE 3}

Daughter, aged 24. Born by spontaneous vertex delivery at term, this patient had an early history very similar to her elder brother's. She was unable to walk by herself until the age of 5 and subsequently attended the same special school. There was little progression in her disability. General medical examination was normal. The optic fundi and visual acuity were normal, and small pupils unreactive to light or accommodation were noted. Nystagmus was present on lateral gaze, the fast phase in the direction of gaze. The remainder of the cranial nerves were normal. Tone was generally increased in the limbs, particularly the legs, but there was no weakness. The tendon reflexes were pathologically brisk and the plantars extensor, but the abdominal reflexes were preserved. There was slight incoordination of the right hand and mild heel-to-shin ataxia on that side. She was unable to do tandem gait. Sensory testing was normal.

\section{CASE 4}

Youngest son, aged 17. He was born normally at term and apparently had relatively normal early milestones, though he did not walk until 18 months to 2 years. He had an infantile febrile convulsion, but no seizures since. His walking has deteriorated slightly, but he is still ambulant. General examination was normal. The pupils were small and unresponsive to light or accommodation. He had nystagmus to the right, present in the primary position of gaze. The other cranial nerves were normal. He had a spastic ataxic gait, with a generalised increase in tone in the limbs though no weakness. The tendon reflexes were pathologically brisk, plantars extensor, and abdominal reflexes preserved. There were mild bilateral cerebellar signs. Sensory examination was normal.

None of the family had evidence of skeletal abnormality or pes cavus, and their pupillary abnormality had been noted since birth. Two patients (daughter and youngest son) were investigated in detail. The results were identical and are detailed below.

\section{INVESTIGATIONS}

Estimations of blood sugar, routine haematology, electrolytes, and liver functions were normal. Protein electrophoresis showed a slight decrease in $\alpha_{1}$ and $\alpha_{2}$ globulins but was otherwise unremarkable. Serological tests for syphilis were negative, and no phytanic acid was detected in the serum. ECGs and EEGs were normal. Sensory and motor nerve conductions were normal in upper and lower limbs. Visual, brain stem, and somatosensory evoked responses showed no abnormality. Computered tomography scans, without contrast, were normal and in particular did not show any evidence of cerebellar atrophy. Tests of autonomic function, including sweating, pulse, and 

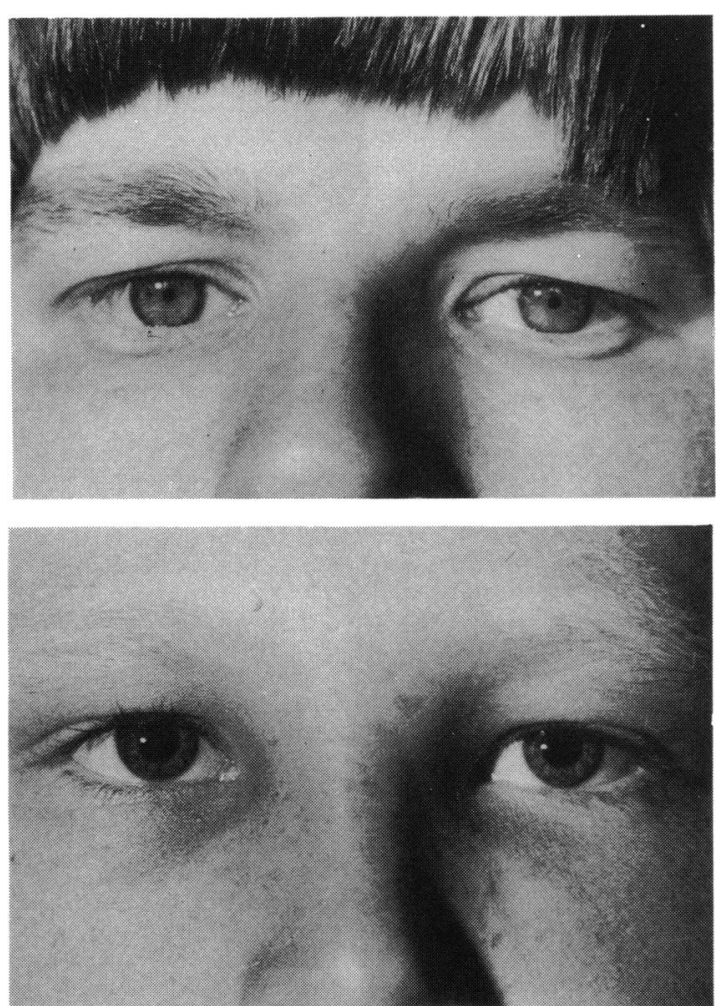

Fig. 2 Affected (above) and unaffected (below) siblings photographed in identical light conditions.

blood pressure response to Valsava and change in posture, were all normal.

A detailed ophthalmological examination was performed on each patient. The pupils in their resting state measured $2 \mathrm{~mm}$ in diameter (Fig. 2). No reaction was observed on accommodation, but when viewed under the slit-lamp there was minimal constriction to bright light. The administration of gutt. adrenalin. $0.1 \%$ had no effect, suggesting that there was no denervation hypersensitivity which would be expected with a sympathetic postganglionic lesion. Cyclopentolate $1 \%$ resulted in minimal dilatation of the pupil. These features suggest that the persistent miosis is due to a congenital absence of the dilator pupillae muscle. This is thought to be the underlying abnormality in congenital miosis. ${ }^{2}$

A formal psychometric assessment showed that both children were functioning in the dull average range with respect to verbal activities, having a verbal IQ of 82 and 86 (youngest son and daughter respectively). The performance IQ of the youngest son was 75 , which is in the borderline subnormal range of intelligence. The score of his sister was slightly higher, with a performance IQ of 82 . Verbal short-term memory was moderately impaired in both.

\section{Discussion}

This family has a hereditary ataxia which is unusual because of the early age of onset and the apparent lack of progression. Although the completed clinical picture resembles most closely hereditary spastic ataxia, the early age of onset and presence of nystagmus makes this a less tenable diagnosis. Clearly, however, they suffer from a hereditary ataxia with pyramidal features which appears to be inherited as an autosomal dominant trait.

Although pupillary abnormalities are described in the hereditary ataxias, the most frequent associations are with optic atrophy, retinal degenerations, and disorders of conjugate gaze. Sjögren ${ }^{3}$ reviewed 91 patients with Friedreich's ataxia and found $12 \%$ had evidence of optic atrophy. It has also been occasionally reported in olivo-ponto-cerebellar atrophy, ${ }^{45}$ though some members of the reported families also showed features of Friedreich's ataxia. The development of optic atrophy has also been associated with both the autosomal dominant and sex-linked recessive forms of spastic paraplegia. ${ }^{67}$ Optic atrophy may accompany hereditary spastic ataxia, and several of the original family described by Sanger Brown showed this feature. In some instances optic atrophy has been found in association with retinal degeneration, ${ }^{89}$ and less commonly secondary to retrobulbar neuritis, ${ }^{1011}$ though the evidence for the latter aetiology is less convincing. Heck ${ }^{12}$ examined 160 cases of Friedreich's ataxia and found 9 cases of retinal degeneration, and this complication is also reported in olivo-pontocerebellar atrophy ${ }^{13}$ and spastic paraplegia. ${ }^{14}$ is Bergstadt et al.${ }^{16}$ described a family with a progressive spastic ataxia and central retinal degeneration which resembled Sanger Brown's patients, although the retinal anomaly distinguished them. Indeed, the presence or absence of retinal degeneration has recently been proposed as a means of classifying the dominantly inherited cerebellar ataxias. ${ }^{17}$

Abnormalities of conjugate gaze are some of the most commonly reported ocular associations but are least commonly reported in hereditary spastic paraplegia. ${ }^{18} \mathrm{~A}$ few cases have been pathologically examined, and these suggest that there are probably 3 main aetiologies. These are degeneration of the supranuclear structures, abnormalities of the oculomotor nuclei, or a myopathy involving the extraocular muscles. Jampel and others ${ }^{19}$ reported a family with spinocerebellar ataxia in which pathological examination showed normal extraocular muscles, cranial nerves, and nuclei, from which he concluded that the abnormality was supranuclear. Similar findings led Koeppen and $\mathrm{Hans}^{20}$ to suggest that supranuclear defects of saccadic movements may be more common than realised, and it seems likely that this is the 
commonest mechanism, though cases of nuclear abnormalities have been reported. Woods and Schaumberg ${ }^{21}$ examined one member of a family with Azorean disease and found degeneration of the oculomotor nuclei, while more extensive nuclear involvement was found in the patient described by Brion and Derecondo. ${ }^{22}$ They reported the pathological findings in a patient with spinocerebellar ataxia and ophthalmoplegia who had degeneration of the nuclei of the third, fourth, sixth, seventh, and twelfth cranial nerves. Finally, Stephens et al. ${ }^{23}$ described a family with a dominantly inherited ataxia showing both features of Charcot-Marie-Tooth disease and Friedreich's ataxia with a progressive external ophthalmoplegia. A post-mortem examination of one case showed normal oculomotor nerves and nuclei with a myopathy of the external ocular muscles. Another case report and review of the literature ${ }^{24}$ suggested the primary defect was predominantly nuclear and that these ultrastructural changes in ocular muscles were secondary to denervation.

Many of the early families with hereditary ataxia had members who showed pupillary abnormalities. Three of Sanger Brown's patients had a sluggish pupillary response to light, and this seems to have been a common finding in early reports. ${ }^{25}$ Complete loss of reaction to light has been reported in olivoponto-cerebellar atrophy, and several patients in Schut' $\mathrm{s}^{5}$ and Chandler and Bebin' ${ }^{26}$ series showed this feature. Ferguson and Critchley observed absent reaction to accommodation in conjunction with hereditary ataxia. ${ }^{27}$ In the same paper these authors described another patient with Argyll-Robertson pupils, and this has also been seen in some cases of Friedreich's ataxia $^{28}$ and Charcot-Marie-Tooth disease. ${ }^{29}$

In congenital miosis the dilator muscle is thought to be either absent or hypoplastic. The pupils seldom exceed $2 \mathrm{~mm}$ in diameter and dilate poorly with mydriatics. The condition may either be inherited as an autosomal dominant or, less commonly, an autosomal recessive trait.$^{30}$ In this pedigree the condition is clearly dominantly inherited. It has been associated with arachnodactly, congenital rubella, and Lowe's oculocerebrorenal syndrome. ${ }^{31-33}$ To our knowledge it has not been reported in conjunction with hereditary ataxia, although interestingly aniridia has. ${ }^{34}$

We thank Dr D. D. Barwick for his neurophysiological assistance, Dr M. Nogues for performing tests of autonomic function, Dr I. Mosquera for photography, Mr J. Welch for psychometric assessments, and Mrs R. J. Dick for her assistance with the manuscript.

\section{References}

1 Brown S. On hereditary ataxia with a series of twenty-one cases. Brain 1892; 15: 250-68.
2 Walsh FB, Hoyt FN. Clinical neuro-ophthalmology. 3rd ed. Baltimore: Williams and Wilkins, 1969; 1: 490.

3 Sjögren T. Klinische und erbiologische untersuchungen über die heredoataxien. Acta Psychiatr Scand (Suppl) 1943; 27: 1-197.

4 Woodworth JA, Bechett RS, Netsky MG. A composite of hereditary ataxias. Arch Intern Med 1959; 104: 594-606.

5 Schut JN. Hereditary ataxia. Clinical study through six generations. Arch Neurol Psychiatr 1950; 63: 535-68.

6 Sutherland JM. Familial spastic paraplegia: its relation to mental and cardiac abnormalities. Lancet 1957; ii: 169-70.

7 Johnston AW, McKusick VA. A sex linked recessive form of spastic paraplegia. Am J Hum Genet 1962; 14: 83-93.

8 Carpenter S, Schumacher GA. Familial infantile cerebellar atrophy associated with retinal degeneration. Arch Neurol 1966; 14: 82-94.

9 Weiner CP, Konigsmark BW, Stoll J; Magladery JW. Hereditary olivo-ponto-cerebellar atrophy with retinal degeneration. Arch Neurol 1967; 16: 364-76.

10 Andre-Van-Leeuen M, Van Bogaert L. Hereditary ataxia with optic atrophy of the retrobulbar neuritis type and latent pallidoluysian degeneration. Brain 1949; 72: 340-63.

11 Bickerstaff ER. Hereditary spastic paraplegia. J Neurol Neurosurg Psychiatry 1950; 13: 134-45.

12 Heck AF. Presumptive X-linked intermediate transmission of retinal degenerations. Arch Ophthalmol 1963; 70: 143-9.

13 Eadie MJ. Olivo-ponto-cerebellar atrophy variants. In: Vinhen PJ, Bruyn GW, eds. Handbook of clinical neurology. Amsterdam: North Holland, $1975 ; 451-7$.

14 Mahloudji M, Chuke PO. Familial spastic paraplegia with retinal degeneration. Johns Hopkins Med J 1968; 123: 142-4.

$15 \mathrm{Kjellin} \mathrm{KJ}$. Familial spastic paraplegia with amyotrophy, oligophrenia and central retinal degeneration. Arch Neurol 1959; 1: 133-40.

16 Bergstadt M, Johenson S, Maller R. Hereditary spastic ataxia with central retinal degeneration and vestibular involvement. A clinical report on a family. Neurology (Minneap) 1962; 12: 124-32.

17 Harding A. The clinical features of the late onset autosomal dominant cerebellar ataxias. Brain 1982; 105: 1-28.

18 Alajouanine T, Nick J. Paraplégie spasmodique familiale avec troubles cerebelleux et paralysie verticale du regard. Rev Neurol (Paris) 1951; 84: 182-5.

19 Jampel RS, Okazaki H, Bernstein H. Ophthalmoplegia and retinal degeneration associated with spinocerebellar ataxia. Arch Ophthalmol 1961; 66: 247-59.

20 Koeppen AH, Hans MB. Supranuclear ophthalmoplegia in olivo-ponto-cerebellar degeneration. Neurology (Minneap) 1976; 26: 764-8.

21 Woods BT, Schaumberg HH. Nigro-spino-dentatal degeneration with nuclear ophthalmoplegia. J Neurol Sci 1972; 17: 149-66.

22 Brion S, DeRecondo J. Ophtalmoplégie nucléaire progressive et hérédo-dégénerescence spino-cérébelleuse. Rev Neurol 1967; 116: 383-400.

23 Stephens J, Hoover M, Denst J. On familial ataxia and neural amytrophy and their association with progressive external ophthalmoplegia. Brain 1958; 81: 556-66.

24 Bastiaensen LAK, Jasper HHJ, Stadhouders AM, Egberink GJM, Korten JJ. Chronic progressive external ophthalmoplegia in a heredo-ataxia: neurogenic or myogenic? Acta Neurol Scand 1977; 56: 483-507.

25 Bell JM, Carmichael EA. On hereditary ataxia and spastic paraplegia. Treasury of human inheritance. Cambridge: Cambridge University Press, 1939: 4 (3): 196.

26 Chandler JJ, Bebin J. Hereditary cerebellar ataxia: Olivo-pontocerebellar type. Neurology (Minneap) 1956; 6: 187-95.

27 Ferguson FR, Critchley M. A clinical study of a heredofamilial disease resembling disseminated sclerosis. Brain 1929;52:203-55.

28 Wells FE. Friedreich's disease: a report of five cases. JAMA 1888; 11: 303-4.

29 Alajouanine T, Castaigne P, Cambier J, Escourolle R. Maladie de Charcot-Marie: étudeanatomo-clinique.PresseMed 1967;75:2745. 
30 Polomeno RC, Milot J. Congenital miosis. Can J Ophthalmol $1979 ; 14: 43-6$.

31 Lutman FC, Neel JU. Inheritance of arachnodactyly, ectopia lentis and other congenital anomalies (Marfan's syndrome) in the 'E' family. Arch Ophthalmol 1949; 41: 276-305.

32 Zimmerman LE. Histopathologic basis for ocular manifestations of congenital rubella syndrome. Am J Ophthalmol 1968; 65: 837-69.

33 Fisher NF, Hallet J, Carpenter G. Oculocerebrorenal syndrome of Lowe. Arch Ophthalmol 1967; 77: 642-5.

34 Gillespie FD. Aniridia, cerebellar ataxia and oligophrenia in siblings. Arch Ophthalmol 1965; 73: 338-41. 